\title{
Engaging men to transform inequitable gender attitudes and prevent intimate partner violence: a cluster randomised controlled trial in North and South Kivu, Democratic Republic of Congo
}

Julia Vaillant, ${ }^{1}$ Estelle Koussoubé, ${ }^{1}$ Danielle Roth, ${ }^{2}$ Rachael Pierotti, ${ }^{1}$ Mazeda Hossain (D) , ${ }^{3}$ Kathryn L Falb (D) ${ }^{4}$

To cite: Vaillant J, Koussoubé E, Roth $\mathrm{D}$, et al. Engaging men to transform inequitable gender attitudes and prevent intimate partner violence: a cluster randomised controlled trial in North and South Kivu, Democratic Republic of Congo. BMJ Global Health 2020;5:e002223. doi:10.1136/ bmjgh-2019-002223

Handling editor Seye Abimbola

- Additional material is published online only. To view please visit the journal online (http://dx.doi.org/10.1136/ bmjgh-2019-002223).

Received 11 December 2019 Revised 18 March 2020 Accepted 7 April 2020

Check for updates

(c) Author(s) (or their employer(s)) 2020. Re-use permitted under CC BY-NC. No commercial re-use. See rights and permissions. Published by BMJ.

For numbered affiliations see end of article.

Correspondence to Dr Julia Vaillant; jvaillant@worldbank.org

\section{ABSTRACT}

Introduction The study objective was to understand the effectiveness of Engaging Men through Accountable Practice (EMAP), a group-based discussion series which sought to transform gender relations in communities, on intimate partner violence (IPV), gender inequitable attitudes and related outcomes.

Methods A two-armed, matched-pair, cluster randomised controlled trial was conducted between 2016 and 2018 in eastern Democratic Republic of Congo. Adult men $(n=1387)$ and their female partners $(n=1220)$ participated in the study. The primary outcomes of the study were female report of past year physical and/ or sexual IPV and men's intention to commit violence. Secondary outcomes included men's gender attitudes, women's economic and emotional IPV, women's perception of negative male behaviours and perceived quality of the relationship.

Results Men in EMAP reported significant reductions in intention to commit violence ( $\beta=-0.76$; $S E=0.23 ; p<0.01$ ), decreased agreement with any reason that justifies wife beating $(\mathrm{OR}=0.59 ; \mathrm{SE}=0.08 ; \mathrm{p}<0.01)$ and increased agreement with the ability of a woman to refuse sex for all reasons $(\mathrm{OR}=1.47 ; \mathrm{SE}=0.24 ; \mathrm{p}<0.05)$, compared with men in the control group. We found no statistically significant differences in women's experiences of IPV between treatment and control group at follow-up (physical or sexual IPV: adjusted $\mathrm{OR}=0.95 ; \mathrm{SE}=0.14 ; \mathrm{p}=0.71$ ). However, female partners of men in EMAP reported significant improvements to the quality of relationship ( $\beta=0.28$; $\mathrm{p}<0.05)$ and significant reductions in negative male behaviour $(\beta=-0.32 ; p<0.01)$.

Conclusion Interventions engaging men have the potential to change gender attitudes and behaviours in conflict-affected areas. However, while EMAP led to changes in gender attitudes and behaviours related to perpetration of IPV, the study showed no overall reduction of women's experience of IPV. Further research is needed to understand how working with men may lead to longterm and meaningful changes in IPV and related gender equitable attitudes and behaviours in conflict areas. Trial registration number NCT02765139.

\section{Key questions}

What is already known?

- Intimate partner violence is a pervasive issue in conflict-affected contexts, including in eastern Democratic Republic of Congo.

- The evidence base for effective interventions to engage men to reduce violence in such settings is limited.

\section{What are the new findings?}

- This cluster randomised controlled trial evaluates an approach, Engaging Men through Accountable Practice, which is a male-only discussion group, to critically reflect and challenge gender attitudes and reduce intimate partner violence, while facilitation and groups are accountable to women's needs in the community.

- The study found significant improvements in men's intention to commit violence and gender equitable attitudes and behaviours, as well as improvement in relationship quality as reported by women, but not reductions in their female partner's report of past year intimate partner violence.

What do the new findings imply?

- Longer study follow-up periods are needed to determine if observed changes in relationship quality and men's increased engagement in housework may result in reductions in intimate partner violence in the long term.

- Additional programme components may be needed to realise reductions in intimate partner violence for women, including community norm change interventions.

\section{INTRODUCTION}

Globally, one in three women worldwide report experiencing intimate partner violence (IPV) in their lifetime. ${ }^{1}$ In conflict-affected settings, the prevalence of such violence may be higher as a recent population-based survey 
from South Sudan reports that over $60 \%$ of women report physical IPV from their male partners ${ }^{2}$ and nearly $70 \%$ of women in Democratic Republic of Congo (DRC) experienced at least one form of lifetime physical, sexual or emotional IPV within the 2013-2014 Demographic and Health Survey. ${ }^{3}$ Increased risk of men's use of violence against women may occur in these settings due to a range of factors including normalisation of violence, increased traumatic experiences within families and economic instability. ${ }^{4}$ Recent evidence also indicates that violence against women and girls occurs early and over the life course in eastern DRC - with as many as half of all girls as young as age 13 reporting some form of violence in the past 12 months. ${ }^{5}$ Engaging men may be one strategy to reduce these levels of violence. In the vast majority of cases of violence, men and boys are the perpetrators, and it is recognised that working with men to change genderunequal attitudes, beliefs and behaviours is an important component in reducing the incidence of IPV. ${ }^{6}$ However, evidence of effective interventions that work with men to reduce their likelihood of perpetration of IPV, particularly in low and middle-income countries that grapple with armed conflict is sparse. Additionally, the available evidence points to self-reported attitudinal changes, but not meaningful changes in violence perpetration. ${ }^{6} 7$ It is also worth noting that programmatic approaches to engaging men vary widely in intensity and target populations as well as content of the intervention, including the extent to which power dynamics, violence and gender equity are addressed in the programme.

This study evaluates the impact of Engaging Men through Accountable Practice (EMAP), a 16-week menonly discussion group intervention aiming to prevent IPV and transform attitudes and behaviours around gender and power in the couple. A study in Rwanda evaluating the effect of gender-transformative couple's discussion groups found a significant impact both on reducing IPV and increasing women's decision-making and men's participation in housework. ${ }^{8}$ Another impact evaluation of a violence prevention programme at the community level in Uganda (SASA!, which means 'now' in Kiswahili) found decreases in acceptability of violence and nonsignificant, yet clear downward reductions in violence. ${ }^{9}$ However, in a conflict-affected setting, working with couples and multilevel, long-term, community intervention such as SASA! may present some safety and implementation challenges. A programme that worked with men in a humanitarian setting to reduce IPV through information, skills and behaviour change in a conflictaffected setting was the International Rescue Committee's (IRC) 'Men in Partnership' intervention piloted in conflict-affected communities in Côte d'Ivoire. The programme comprised male discussion groups that sought to change men's behaviour and promote gender equitable norms. ${ }^{10}$ Results of a cluster randomised controlled trial of the programme showed improvement in attitudes and participation in household tasks and conflict management skills. Suggestive evidence of reduction in IPV was found but was not statistically significant. Building on lessons from 'Men in Partnership', the IRC developed the 'Preventing Violence Against Women and Girls: Engaging Men through Accountable Practice' (EMAP) programme which aimed to maximise potential reductions in IPV through refining the gender equity approach and incorporating in the discussions women's expressions of desired changes to their intimate relationships in order to keep women's voices at the forefront of violence prevention work.

This study contributes to the evidence base on the effectiveness of engaging men to reduce violence against women and girls in three main ways. First, previous studies have suffered from a lack of statistical power, due to small sample sizes. In this study, we use a large sample of men and women. With a sample size of approximately 1300 men and 1200 women in a total of 28 study sites, it ensures that power to detect changes in primary and secondary outcomes is high. Second, a wide set of outcomes is examined, including IPV and attitudes around gender, but also women's decision-making power and intrahousehold cooperation indicators. There is little evidence to date on how gender-transformative interventions change women's economic empowerment and intrahousehold dynamics. Increasing women's agency is important in its own right but it may also be instrumental in reducing violence against women in the longer term. ${ }^{11}$ In addition, increasing the communication and cooperation within a household may enhance its efficiency, which could in turn relax economic stress, a recognised correlate of violence. ${ }^{11}$ Third, the study is set in the North and South Kivu provinces in DRC which have been grappling with vacillating levels of conflict for over two decades. Over the years, the DRC received significant international attention and news coverage for its high rates of sexual violence, ${ }^{12}$ with particular attention placed on sexual violence perpetrated by armed groups. However, IRC's long-term engagement in conflict-affected communities in DRC has shown that women experience gender-based violence $(\mathrm{GBV})$ more often at the hands of someone they know, notably an intimate partner, which is consistent with other conflict-affected settings. ${ }^{13}$ Indeed, IPV may be exacerbated by the disruption of men's social role as economic providers in contexts of instability and insecurity and high levels of psychological stress. ${ }^{14}$ The need for a transformation of gender norms, behaviours and relations associated with violence in this context is evident. The study aims to provide much needed rigorous evidence of the effectiveness of such approaches in humanitarian settings. ${ }^{15}$

\section{METHODS}

\section{Study design}

A two-armed, matched-pair, cluster randomised controlled trial was led by the World Bank's Africa Gender Innovation Lab between 2016 and 2018 in North and South Kivu provinces, DRC, across 30 communities. Sites were 
selected based on where IRC's women's empowerment programming was operational and were subsequently matched based on sociodemographic characteristics. Within each pair of villages, one site was randomised to either treatment or control arms.

Due to security concerns and ongoing armed clashes, baseline data collection was halted in one treatment and one control site in North Kivu (belonging to the same pair), resulting in a final sample of 28 communities (14 control and 14 treatment). The sample size calculation was based on a coefficient of variation of $k=0.3$ and assumed the baseline level of the primary outcome (past year IPV) was $25 \%$. A risk difference of $8.5 \%$ would be detectable at the 0.05 significance level and $80 \%$ power. The randomised controlled trial was complemented by in-depth longitudinal qualitative data collection throughout programme implementation.

\section{Intervention}

EMAP is a group-based discussion series for men that evolved from the Men in Partnership pilot programme and adapted for the DRC context. It sought to transform gender relations in communities by creating a cadre of male allies who practise and promote gender equity and do not use violence, including IPV. The programme was designed to give male participants the tools and knowledge to rethink belief systems and prevent GBV through individual behavioural change. EMAP follows a systematic approach, involving the same group of men participating in weekly discussions with their male peers over 16 weeks. The sessions are approximately 3 hours long and are led by male trained facilitators.

The facilitators also led participant recruitment by assembling groups of men through community networks, describing programme goals to the groups and asking for volunteers to participate. In some communities, local secular and religious leaders were involved in identifying and assembling men who had the potential to be role models for other men in the community. Facilitators also did door-to-door recruitment to generate interest in some communities. Participation to the programme was voluntary in all communities targeted. Topics explored the underpinnings of masculinity; types, causes and consequences of violence against women and girls; and opportunities for positive role modelling and reflection on their own power and privilege. Table 1 summarises the weekly topics covered by the programme. Women's groups were established prior to launching male discussion groups to promote accountability to the needs, views and priorities of women in the community. Discussion topics that arose in the women's groups and other feedback were given to the men's groups throughout the intervention and their reflections were incorporated into the facilitators' approach.

Men in the control villages participated in non-gender norms-related alternative group sessions, the topic of which was chosen by the group members. These activities included rabbit and chicken raising, driving classes and enhanced farming methods, among others. Participants in livelihood activities met for no more than 3 hours a week.

All the study sites, either treatment or control, were in areas with an established IRC Women's Protection and Empowerment Program, which included activities such as case management support for female survivors, women's safe space activities and technical capacity building for local women's community-based organisations, and GBV awareness-raising and sensitisation activities. While IRC's presence in the sites may have influenced reporting and perpetration patterns, random assignment of villages to either the EMAP or control arm ensures that there should be no systematic difference in these patterns across treatment status.

\section{Target population}

Adult men, aged 18 years and older, were eligible to participate in the study. Additional inclusion criteria included having lived in the community for at least 6 months with plans to continue living there for at least an additional 6 months, ability to actively participate in the group, noninvolvement with an ongoing evaluation of adolescent girl programming that was operational in some sites and committing to not perpetrate violence for the duration of the intervention. Female partners of men were also interviewed if they were above 15 years of age. For polygamous households, the first wife was interviewed.

\section{Data collection}

Baseline data collection occurred between April and September 2016 and a follow-up survey was conducted between September and December 2017 to allow assessment of past year changes. Men and their female partners were invited to participate in the interviews. The study was conducted among men who volunteered to participate in the men's activity, either EMAP or the control activity. They did not know which intervention would be rolled out in their community at the time of recruitment. All men who were enrolled to participate in the activity, and their female partners, were then invited to participate in the study.

All data were collected electronically on tablets (computer-assisted personal interviewing) equipped with the software SurveyCTO and by gender-matched enumerators. For sensitive outcomes, audio computerassisted self-interviews were used in order to limit potential under-reporting, using SurveyCTO as well. The survey was developed in French and subsequently translated and back translated into Swahili, Mashi and Kinyarwanda languages.

At baseline, 1387 men and 1220 women were interviewed. Loss to follow-up was low as $97 \%$ of male and $96 \%$ of female baseline respondents were retained at endline. Figure 1 demonstrates the Consolidated Standards of Reporting Trials diagram. The most common reason for attrition was inability to locate the respondent, followed by refusal and having moved to a different location. 
Table 1 EMAP men's group weekly session topics

Session title Goals

Section 1: Understanding gender, power and accountability to women and girls

1. Introduction Introduce EMAP; discuss goals and expectations for the group; think about the society we live in.

2. Understanding gender

Explore what the lives of women would look like in a community where no violence, discrimination and disrespect against women and girls existed; explore how men and women are socialised to think and act.

3. Gender roles in my home

Understand the different tasks that women, men, girls and boys are expected to do during a day; understand how to have respectful discussions with women in our lives.

\begin{tabular}{|c|c|}
\hline 4. Stages of change & $\begin{array}{l}\text { Understand and practise accountable discussions; commit to changes in the } \\
\text { home; begin making a personal action plan for change. }\end{array}$ \\
\hline 5. Violence and manhood & Understand how violence impacts ideas of manhood. \\
\hline 6. Understanding power and rights & $\begin{array}{l}\text { Understand the different types of power; understand how status and privilege } \\
\text { operate in the community; explore the concept of rights. }\end{array}$ \\
\hline 7. Understanding power in the home & $\begin{array}{l}\text { Understand power in the home; analyse one's own use of power; practise } \\
\text { accountable discussions. }\end{array}$ \\
\hline
\end{tabular}

Section 2: Understanding violence against women and girls

8. Understanding violence against women Understand the different types and root causes of VAWG. and girls

\begin{tabular}{|c|c|}
\hline 9. Sexual violence & $\begin{array}{l}\text { Understand what sexual assault and rape are; explore harmful beliefs and } \\
\text { myths about sexual violence. }\end{array}$ \\
\hline 10. Intimate partner violence (IPV) & $\begin{array}{l}\text { Understand why IPV occurs; explore root causes of IPV; understand that IPV is } \\
\text { selective. }\end{array}$ \\
\hline 11. Taking responsibility & $\begin{array}{l}\text { Recognise our thoughts, feelings and emotions; take responsibility for our } \\
\text { emotions and actions. }\end{array}$ \\
\hline 12. Consequences of violence & $\begin{array}{l}\text { Understand the consequences of violence on individuals, families and } \\
\text { communities; reflect on why talking about violence may be difficult. }\end{array}$ \\
\hline \multicolumn{2}{|c|}{ Section 3: Being an ally to women and girls } \\
\hline 13. Supporting survivors of violence & $\begin{array}{l}\text { Discuss victim blaming and how to support survivors of violence; understand } \\
\text { what it means to be an ally to women and girls. }\end{array}$ \\
\hline 14. Healthy relationships & $\begin{array}{l}\text { Explore the characteristics of healthy versus unhealthy relationships; reflect on } \\
\text { discussions with women. }\end{array}$ \\
\hline 15. Being an ally in the community & $\begin{array}{l}\text { Understand what it means to be an ally in the community; reflect on helpful } \\
\text { behaviours; identify key actions for change. }\end{array}$ \\
\hline 16. Reflections & $\begin{array}{l}\text { Reflect on what we have learnt and the changes we have committed to over the } \\
\text { group; identify ways to continue being accountable to women and girls. }\end{array}$ \\
\hline
\end{tabular}

EMAP, Engaging Men through Accountable Practice; VAWG, violence against women and girls.

\section{Measures}

EMAP was evaluated on the following domains: (1) IPV, (2) quality of the couple's relationship, (3) gender attitudes and acceptance of violence, (4) intrahousehold cooperation, (5) women's decision-making power, and (6) gendered division of household tasks. Detailed variable construction is presented in table 2 .

\section{Ethics}

All participants completed informed consent and established global guidelines on conducting ethical violence against women research were followed. ${ }^{16}$ Ethical approval was received from IRC's Internal Review Board and the DRC Ministry of Women, Family, and Children. Violence questions were only asked among female partners in order to minimise any safety concerns. Referrals were available to IRC's women and protection services for any woman who wished to have additional support after the survey was completed.

\section{Analysis}

We estimate intention-to-treat effects of the EMAP programme on experience of violence and other secondary outcomes at endline by using: (1) logistic models (and estimated OR) for all binary outcomes; and (2) linear models for continuous outcomes. We estimate both unadjusted and adjusted models. In the latter models, we control for the following baseline 


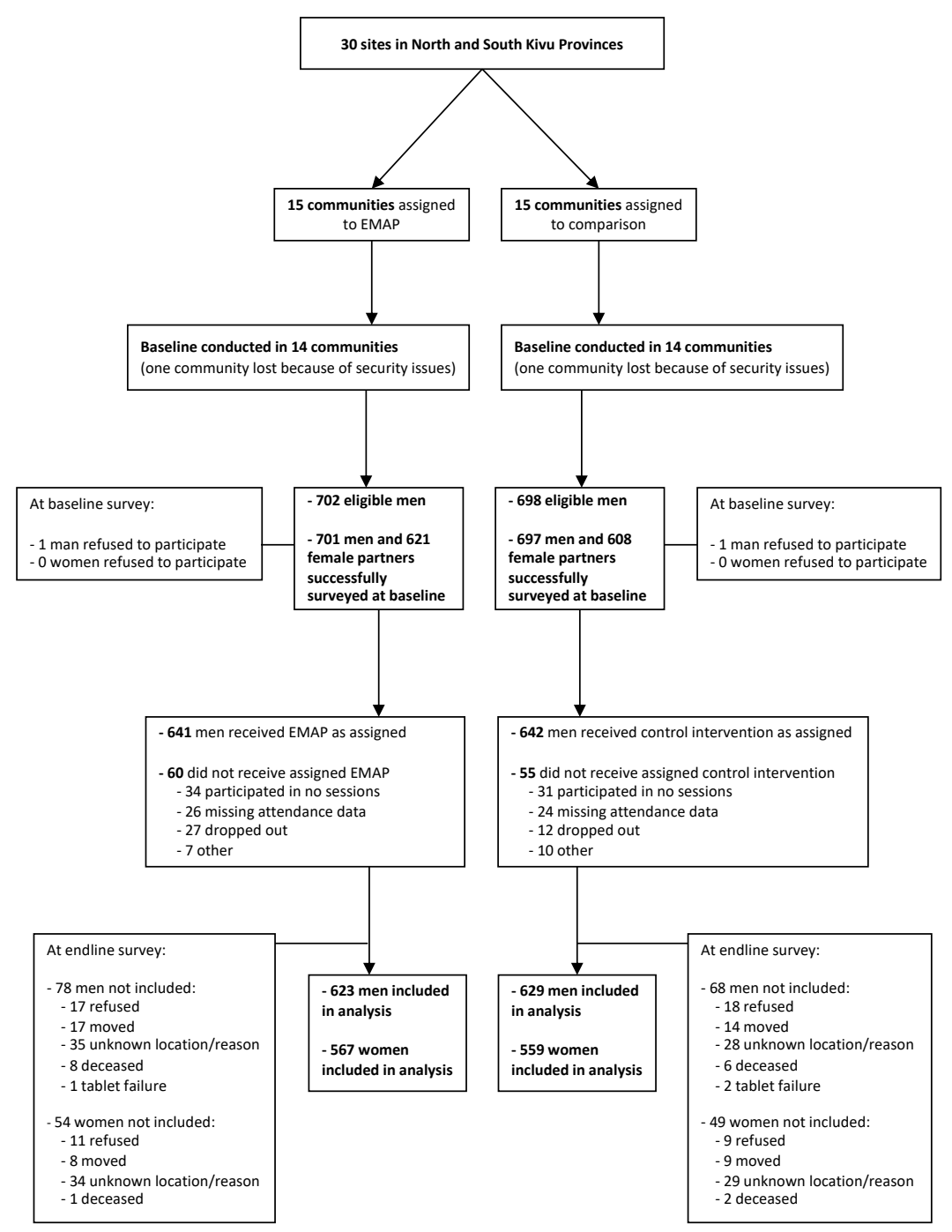

Figure 1 EMAP trial profile.

characteristics: household size, men and women's age, men and women's education and the language of the interview; and baseline values of the outcome indicators for outcomes collected at baseline and endline. Control variables selected are commonly used in the literature and are likely to influence the outcomes of interest, therefore including them in the analysis may increase the precision of our estimates. For all analyses, SEs are clustered at the site level and we include site pairs dummies in all regressions. We use Stata (V.13) for all the analyses.

\section{Patient \& Public Involvement}

Community members were first involved in this study during recruitment for participation in the EMAP programme or the alternative intervention arm. The activities conducted in the latter alternative arm were guided by the desires of the community. In addition, the EMAP approach is guided by the voices and feedback of women in the community who provide overall direction and insights to changes they would like to see in men's attitudes and behaviours.

\section{RESULTS}

Table 3 presents the overall demographics of the study population by treatment arm. There were no significant differences in demographics across treatment arms at baseline, indicating that randomisation was successful On average, men and women were 41 and 35 years old, respectively, with a wide range of ages, going from 17 to 93 years old for men. $77 \%$ and $44 \%$ of men and women reported some schooling, respectively: $26 \%$ of women 

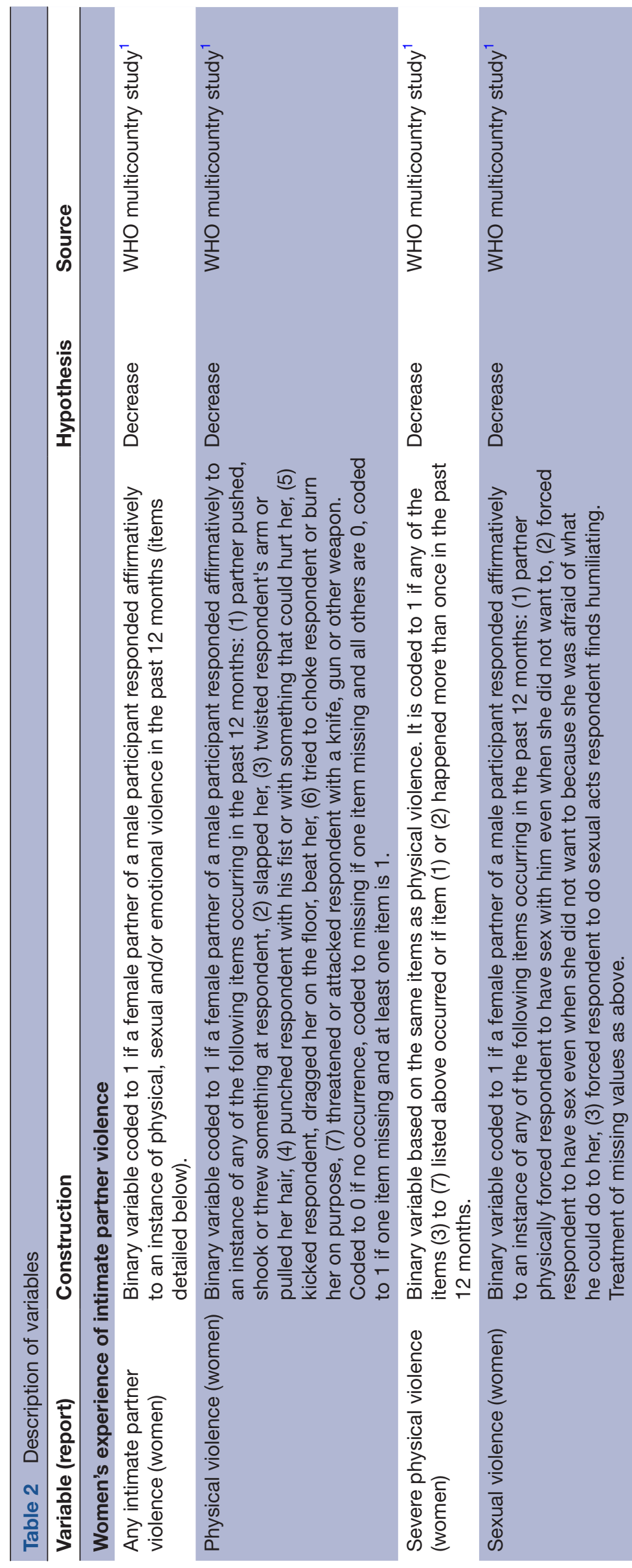

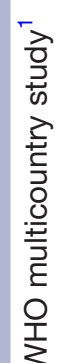

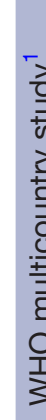

$\Phi^{\circ} \quad \mathrm{L}$

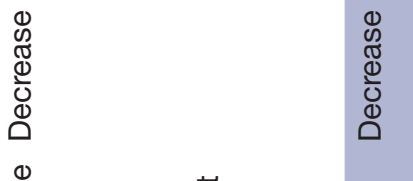

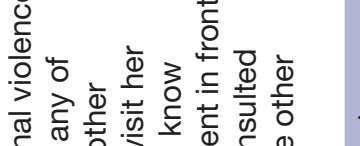

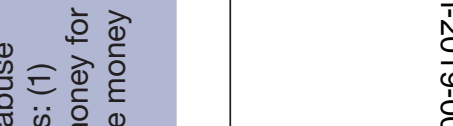

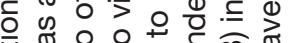

음

ब

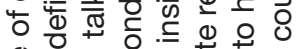

D) की

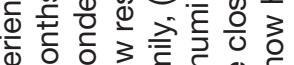

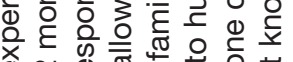

बำ

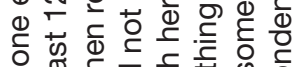

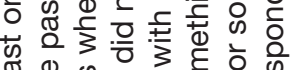

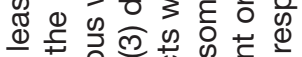

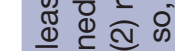

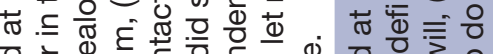

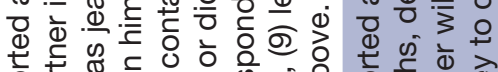

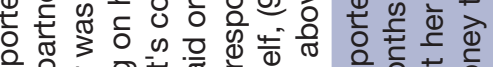

Q

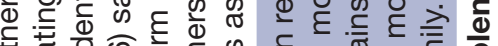

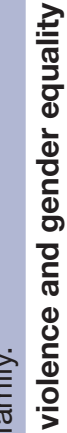

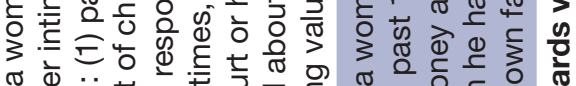

元市

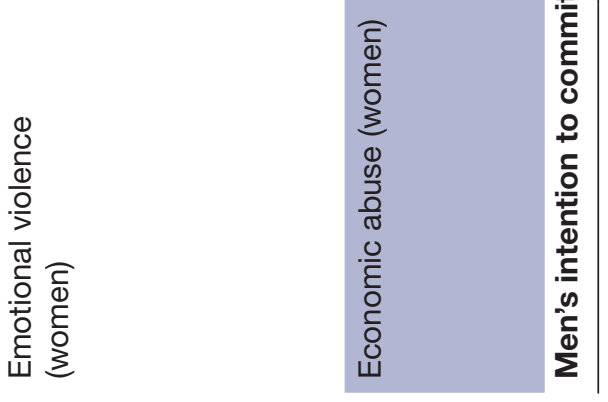




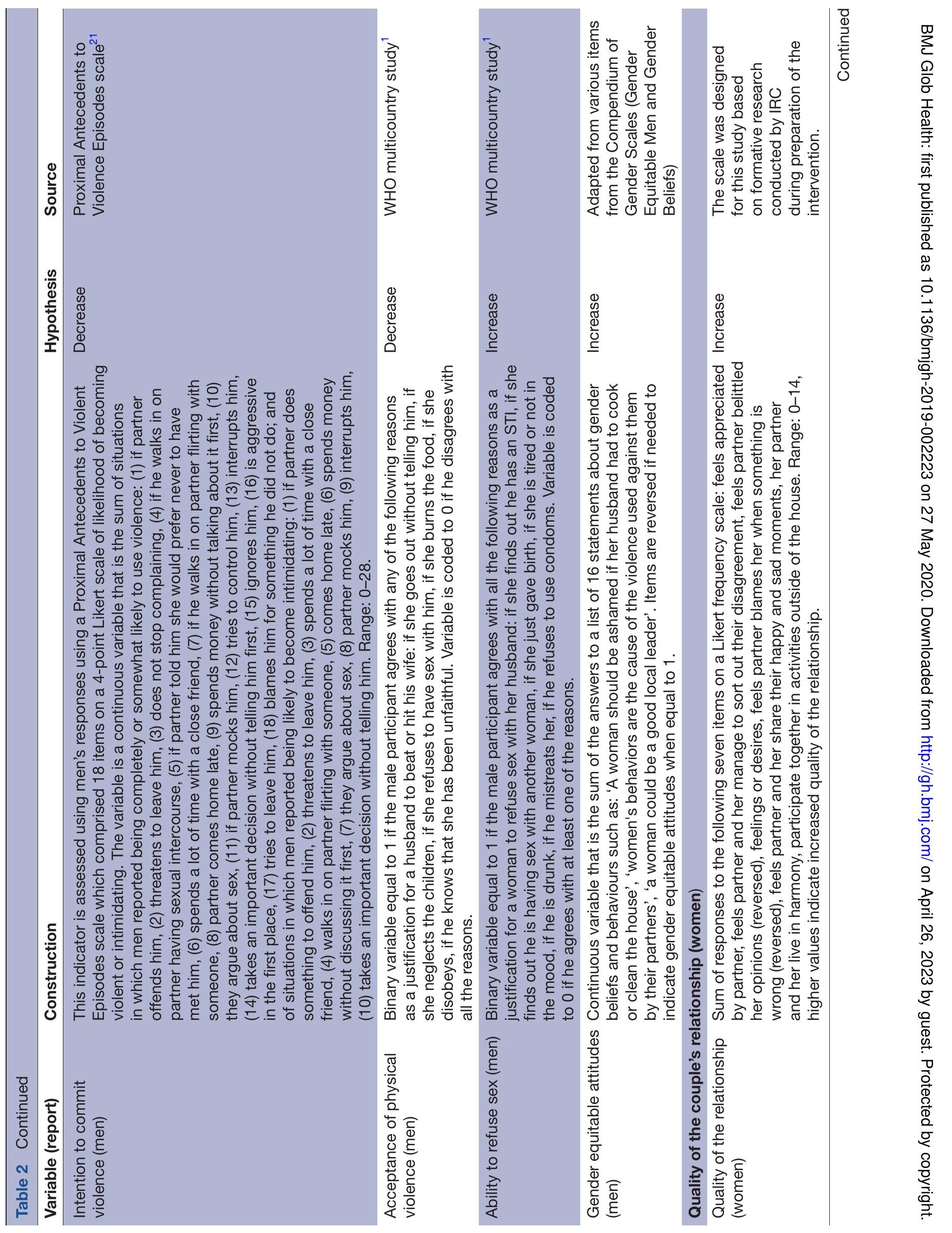



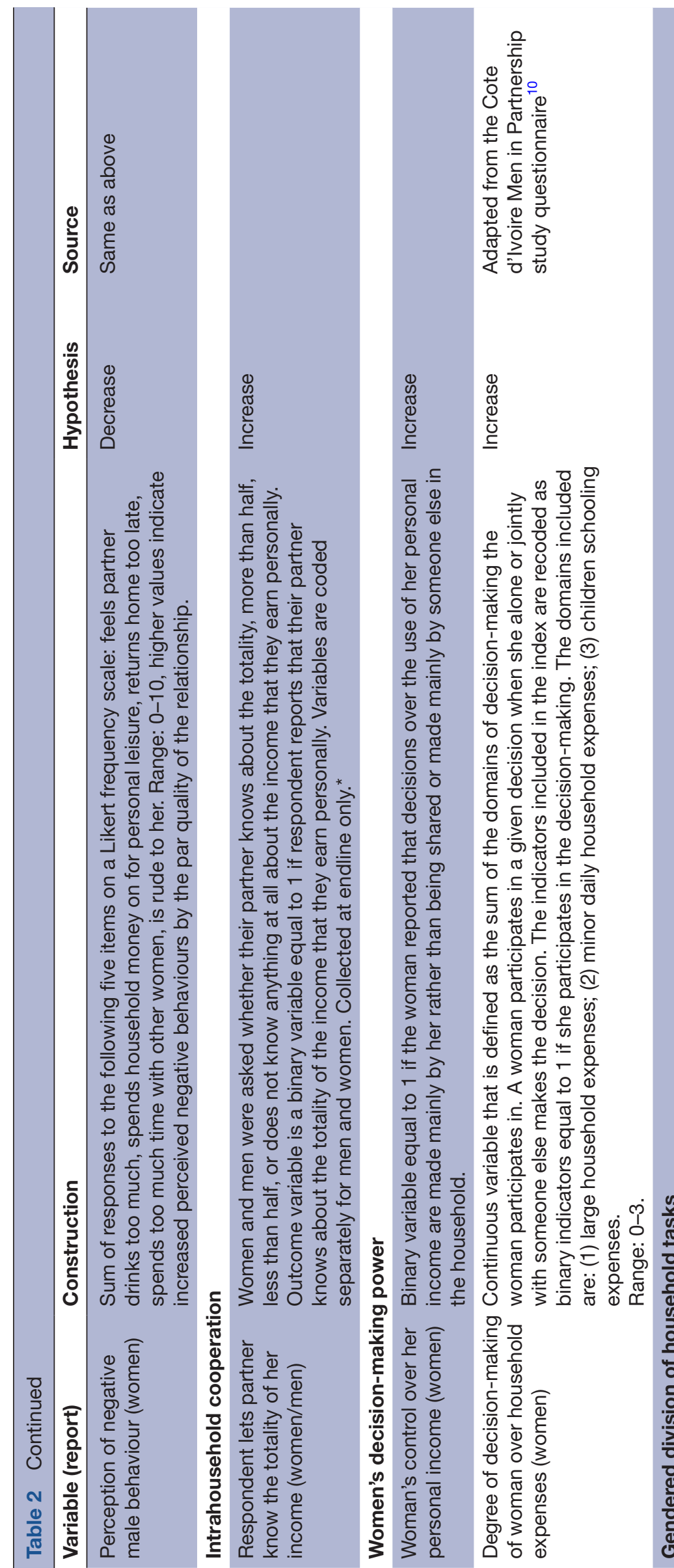

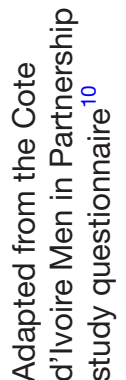

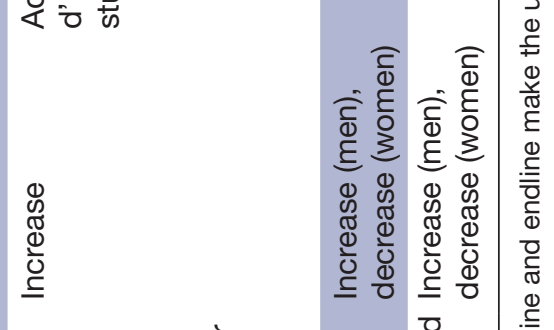

ㅇํㅇ

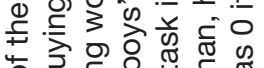
"ᄂ

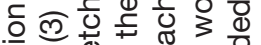
क

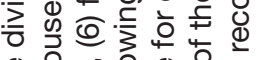

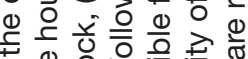

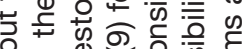
o $₫$ व

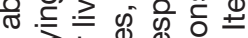

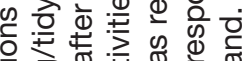
की

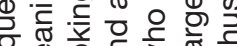
응 $\frac{10}{0} 3 \frac{0}{\pi}$

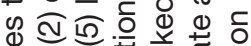
(1)

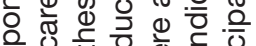
की 는

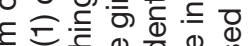

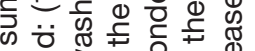
응 300

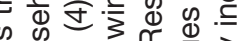

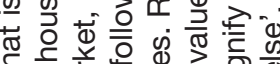

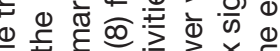

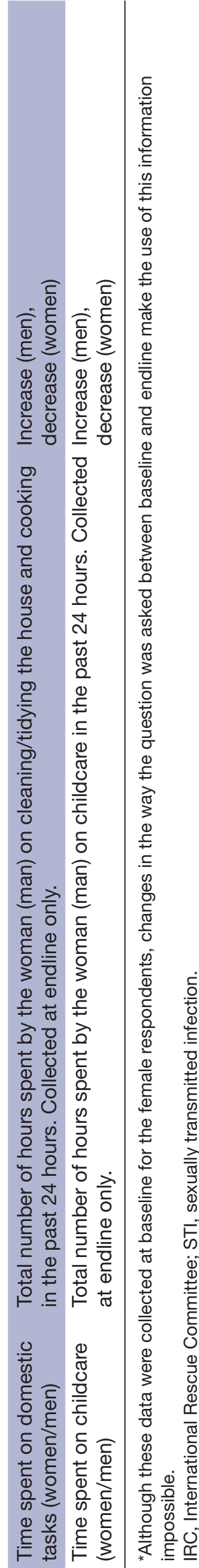

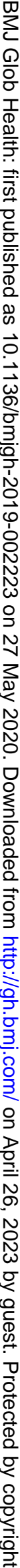


Table 3 Baseline demographics, overall and by treatment arm

\begin{tabular}{|c|c|c|c|c|c|c|}
\hline \multirow[b]{2}{*}{ Demographics } & \multicolumn{2}{|c|}{ Overall } & \multicolumn{2}{|c|}{ EMAP } & \multicolumn{2}{|c|}{ Control } \\
\hline & $\mathbf{n}$ & $\%$ or mean (SD) & $\mathbf{n}$ & $\%$ or mean (SD) & $\mathbf{n}$ & $\%$ or mean (SD) \\
\hline Men's age (mean) & 1251 & $41.2(25.6)$ & 622 & $41.7(23.8)$ & 629 & $40.8(27.8)$ \\
\hline Women's age (mean) & 1091 & $35.7(24.8)$ & 555 & $36.1(26.9)$ & 536 & $35.3(23)$ \\
\hline Men's schooling & 1091 & & 545 & & 546 & \\
\hline Primary (any) & & $29.6 \%$ & & $30.8 \%$ & & $28.4 \%$ \\
\hline Secondary education or higher (any) & & $47.4 \%$ & & $44.6 \%$ & & $50.2 \%$ \\
\hline Women's schooling & 1126 & & 567 & & 559 & \\
\hline Primary (any) & & $26.4 \%$ & & $25.2 \%$ & & $27.5 \%$ \\
\hline Secondary education or higher (any) & & $17.9 \%$ & & $16.4 \%$ & & $19.5 \%$ \\
\hline Household size (women's report) & 1181 & $7.3(5.5)$ & 591 & $7.3(5.5)$ & 590 & $7.3(5.6)$ \\
\hline Polygamous (women's report) & 1215 & $15.5 \%$ & 602 & $15.1 \%$ & 613 & $16 \%$ \\
\hline
\end{tabular}

EMAP, Engaging Men through Accountable Practice.

have completed primary school and $18 \%$ have completed secondary school or beyond while $30 \%$ of men have completed primary school and $47 \%$ have completed secondary school or beyond. The average household size at baseline was 7.3 members. Programme attendance was high. Across the treatment and control groups, $70.1 \%$ of men attended at least $75 \%$ of sessions, with no significant difference between treatment arms. Less than $5 \%$ of the sample did not participate in any session.

Table 4 shows the baseline and endline means of outcomes of interest, as well as adjusted and unadjusted treatment effects at endline. At baseline, nearly three out of four women reported experiencing some form of physical, sexual and/or emotional IPV in the past year. Nearly half of women reported experiencing any physical and/or sexual IPV and roughly one-quarter reported economic abuse in the past year. At follow-up (1 year after the baseline survey), the (adjusted and unadjusted) results showed no statistically significant differences in women's experiences of IPV between treatment and control groups at follow-up (physical or sexual IPV: adjusted $\mathrm{OR}=0.95 ; \mathrm{SE}=0.14 ; \mathrm{p}=0.71$; any $\mathrm{IPV}$ : adjusted $\mathrm{OR}=0.96 ; \mathrm{SE}=0.12 ; \mathrm{p}=0.74)$. Men in the treatment group reported statistically significant lower levels of intention to become violent or intimidating at follow-up compared with men in the control group (adjusted $\beta=-0.76 ; \mathrm{SE}=0.23$; $\mathrm{p}<0.01)$. Men in the treatment group also reported lower acceptance of wife beating (adjusted $\mathrm{OR}=0.59 ; \mathrm{SE}=0.08$; $\mathrm{p}<0.01)$, and were more likely to believe that a woman has the right to refuse sex (adjusted $\mathrm{OR}=1.47 ; \mathrm{SE}=0.24$; $\mathrm{p}<0.05)$ compared with men in the control group. They also report higher levels of egalitarian gender attitudes compared with men in the control group (adjusted $\beta=1.35 ; \mathrm{SE}=0.15 ; \mathrm{p}<0.01)$.

The quality of the relationship as reported by women increased slightly at follow-up in the treatment group compared with the control group (adjusted $\beta=0.28$; $\mathrm{SE}=0.16 ; \mathrm{p}<0.1)$. Women in the treatment group also reported significantly lower levels of negative male behaviours (adjusted $\beta=-0.32 ; \mathrm{SE}=0.12 ; \mathrm{p}<0.05$ ). Both of these variables are significant only in the adjusted model, which increases the precision of the estimates. Analyses of the impact of EMAP on men's alcohol use as reported by women, which is among the outcomes used to measure men's negative behaviour as perceived by women, show a significant reduction (at 1\%) in the likelihood that men drink often (more than once a week) or every day in the treatment group compared with men in the control group (Results are available on request). Women in the treatment group were significantly more likely to disclose to their partners the totality of their income (adjusted $\mathrm{OR}=1.66 ; \mathrm{SE}=0.21 ; \mathrm{p}<0.01)$. Men are also significantly more likely to disclose to their partners the totality of their income (adjusted $\mathrm{OR}=2.02 ; \mathrm{SE}=0.38 ; \mathrm{p}<0.01$ ).

Although the results do not show any significant impacts of EMAP on women's decision-making power, the results show greater involvement of men in domestic tasks and childcare. As reported by women, levels of involvement in domestic tasks of men in the treatment group were higher than for men in the control group (adjusted $\beta=0.92 ; \mathrm{SE}=0.29 ; \mathrm{p}<0.01)$. Similarly, at endline, men in the treatment group reported an average of 60 min spent on domestic tasks in the past 24 hours against 28 min for the control group (adjusted $\beta=36.01 ; \mathrm{SE}=4.44 ; \mathrm{p}<0.001$ ). They also reported spending significantly more time on childcare: $83 \mathrm{~min}$ in the past 24 hours against $61 \mathrm{~min}$ in the control group (adjusted $\beta=25.63 ; \mathrm{SE}=6.11 ; \mathrm{p}<0.01$ ). It is worth noting that women in the intervention group also reported spending more time on domestic tasks compared with the control group while women in the treatment group reported spending less time on childcare, although the difference is not significant.

In the online supplementary appendix, we provide per-protocol analyses of the impact of high and low attendance to the programme (defined as $75 \%$ or more sessions attended) on primary outcomes of interest. Results show that high attendance is associated with a reduction in physical violence and economic abuse, 


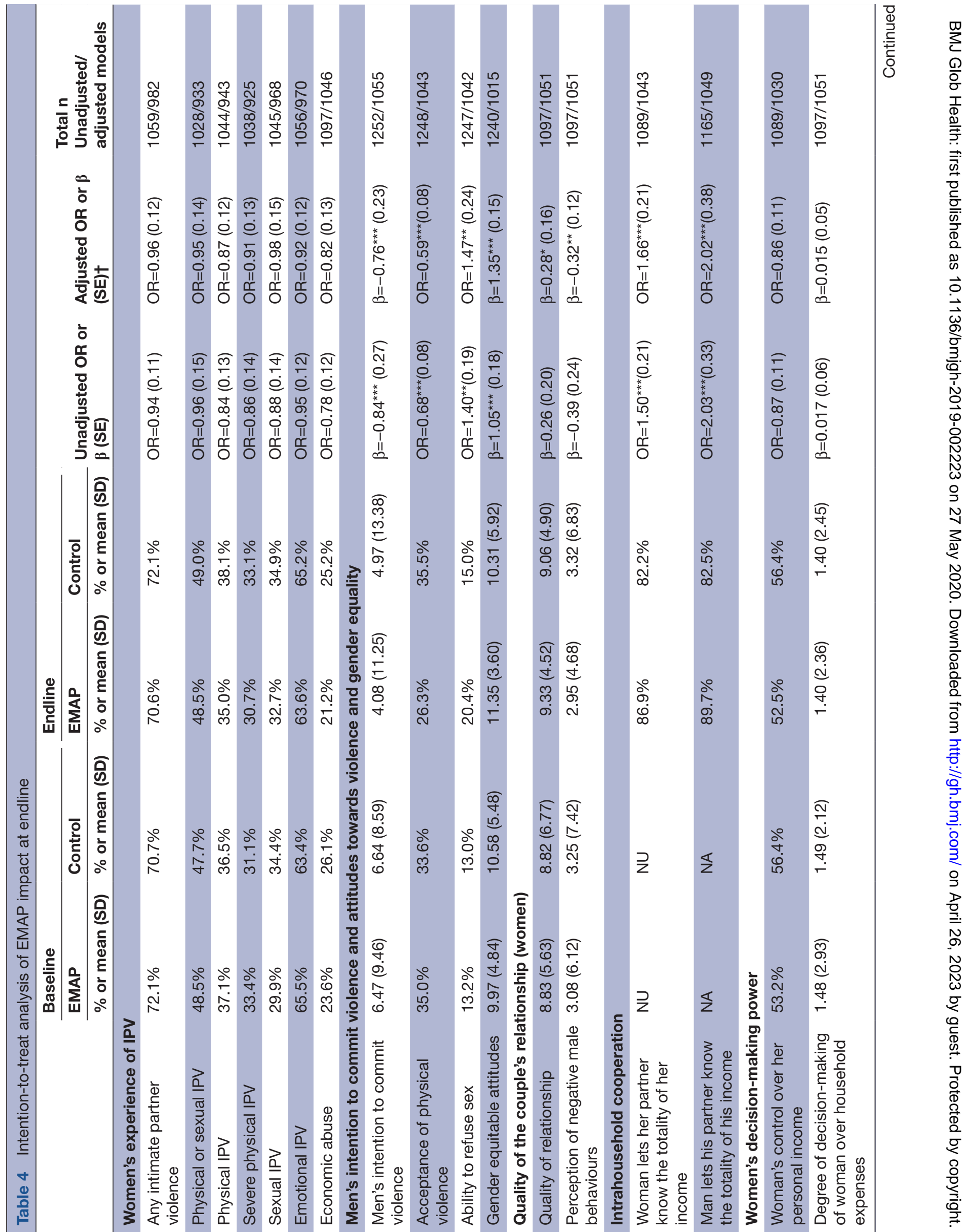




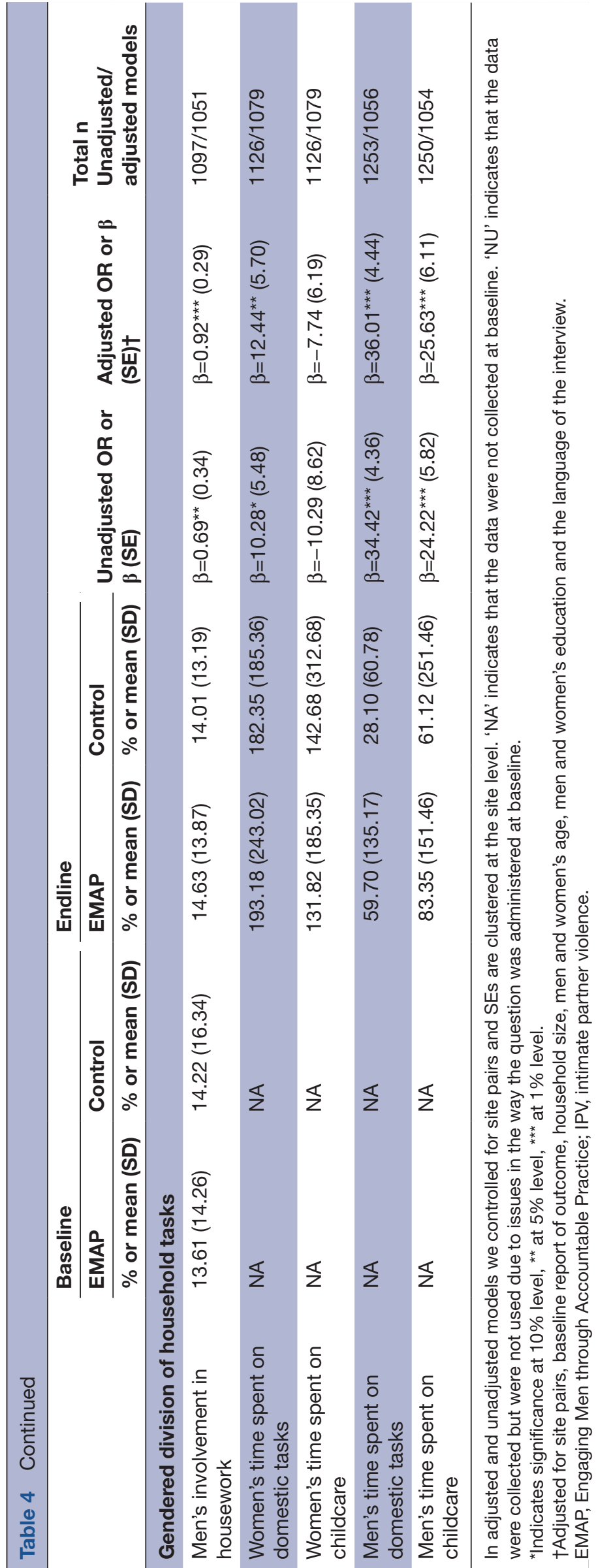

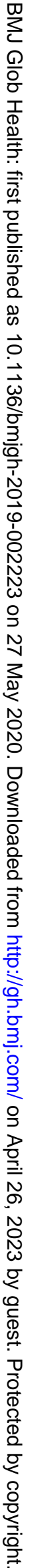


however, the potential bias due to selection on unobservable characteristics limits our ability to draw conclusions from this analysis.

\section{DISCUSSION}

In North and South Kivu, DRC, the frequency of past year IPV is alarmingly high-nearly half of all women in the study sample reported experiencing physical and/or sexual IPV, over $60 \%$ reported emotional violence and approximately one-quarter reported economic abuse. These prevalence rates are comparable to recent Demographic and Health Survey statistics. ${ }^{3}$

This paper presents results of an evaluation of the EMAP programme, which is one of a number of recent efforts to reduce IPV. Men participating in the EMAP intervention reported significant reductions in their intention to commit violence, which is consistent with findings from the Men in Partnership pilot programme in Cote d'Ivoire, which provided the programmatic foundation for EMAP. However, our results show that the frequency of women's reports of IPV remained stagnant between baseline and endline across both treatment and control arms. On the other hand, programme participation did lead to changes in secondary outcomes. EMAP led to an improvement in men's gender attitudes, a reduction in their support for violence against women and an increase in support for a woman's right to refuse to have sex. Moreover, EMAP resulted in behavioural changes that align with those reported attitudinal shifts, including greater participation of men in housework. Intrahousehold cooperation improved as respondents reported sharing more information about their income with their spouses. In addition, women reported that the quality of their relationship improved, and that men's negative behaviours (as perceived by women) decreased in frequency.

The discrepancy between men's reduced intention to commit violence and women's reporting of IPV could be due to a number of factors. First, men's intention around IPV perpetration and attitudes about gender may not have actually changed and differences between treatment and control could be an artefact of social desirability bias. On the other hand, men's intention to commit violence may have been reduced, but they are in need of additional skills, such as emotional regulation or communication skills, in order to not perpetrate violence during heightened instances of tension or disagreement in the household. The Men in Partnership pilot included activities on hostility and conflict management skills. However, this was not included in the DRC EMAP intervention.

The EMAP intervention also resulted in men's behavioural changes, including greater involvement in housework. Since no significant changes in IPV were found, these findings point to the possibility that some types of change were easier or more palatable than others. Perhaps men were willing to reallocate the burden of household labour and consult more often with their wives, as long as the gender hierarchy within the household remained intact. An in-depth qualitative study of the EMAP programme found that although men changed their everyday practices in terms of housework and beliefs of what constitutes a 'woman's work', men undermined the overall process of gender transformation by maintaining power and control over the objectives and processes of change, rather than demonstrating true commitment to gender equality. ${ }^{17}$ To realise reductions in IPV, it may be important to address other factors, in addition to gender attitudes and norms, especially in conflict-affected settings. For instance, addressing economic stress may be an important component of efforts to reduce IPV. A recently completed economic empowerment intervention in eastern DRC found strong trends towards the reduction of IPV 18 months after the intervention. ${ }^{18}$ Although findings were not significant, which was possibly due to being underpowered for this secondary outcome, the study points to the importance of addressing economic drivers of IPV, particularly as it relates to significant improvements in mental well-being and reduction of economic stress among participants as potential mechanisms to reduce IPV. ${ }^{18}$ Indeed, qualitative research from South Kivu, DRC, suggests that couples experiencing IPV primarily attribute violence to the male's alcohol use and financial stress, which are particularly salient factors in a conflict-affected environment where economic opportunities are inhibited by insecurity and instability. ${ }^{19}$ Similar findings have been documented in other conflict-affected settings. ${ }^{20}$ Additional research is needed to determine whether the addition of women's economic strengthening components to EMAP or other engaging men programming would result in increased reductions of IPV. ${ }^{7}$ Another alternative would be the inclusion of women in at least some of the sessions, in a carefully designed intervention, to help promote accountability and transform power relations. ${ }^{21}$ Recent studies have shown positive results of similar programmes for couples, ${ }^{8}$ however more research is needed to understand the circumstances under which these types of programmes are safe and effective. ${ }^{22}$ In addition, programming targeting social norms change at the community level should be considered. Complementing EMAP with work with community leaders may be key to alleviate some of the social pressure to conform to certain behaviours that may have limited the effectiveness of an individual behaviour change intervention. While effective in reducing IPV, this type of intervention may be challenging to implement in humanitarian settings. ${ }^{9}$ Programming modalities for social norms change in humanitarian settings deserves further exploration.

Interpretation of the study findings should be done with limitations in mind. First, study outcomes are selfreported and may be subject to social desirability bias that would lead to under-reporting or over-reporting. Efforts were undertaken to reduce this for the primary outcome by using women's reports of IPV, collected using self-administered questionnaires, rather than men's 
reports of IPV perpetration. Second, the control group received an alternative treatment that included lighttouch trainings that could have led to improvements in the economic standings of households. Although the frequency of IPV did not change substantially between baseline and endline in either treatment or control arms, it is possible that the alternative treatment may have dampened any potential increases in IPV that may have occurred in its absence. Finally, our findings rely on a short-term follow-up; we cannot exclude possible longer term impacts of the programme on IPV.

Despite the null impact on reducing IPV, the EMAP programme significantly improved the quality of relationships among couples. It also led to changes in men's behaviour often associated with IPV, such as men's alcohol consumption, as well as changes in gender attitudes and men's intention to commit violence. This suggests the possibility of long-term improvements in well-being that could break the cycle of violence. Gender inequality is deeply entrenched in North and South Kivu and EMAP may be an important component of a more comprehensive and holistic approach to reducing men's use of IPV.

\section{Author affiliations}

${ }^{1}$ Africa Gender Innovation Lab, World Bank, Washington, DC, USA

${ }^{2}$ Violence Prevention and Response Unit, International Rescue Committee, Tunis, Tunisia

${ }^{3}$ Department of Global Health and Development, London School of Hygiene \& Tropical Medicine, London, UK

${ }^{4}$ Airbel Impact Lab, International Rescue Committee, Washington, DC, USA

Twitter Mazeda Hossain @MazedaHossain

Acknowledgements The study team thanks the women and men who participated in the EMAP programme and study and the International Rescue Committee Women's Protection and Empowerment team. The authors also thank the following people for their research assistance or contributions during the various phases of the project: Theresita Bakemore, Caroline Bora, Andre Cishugi, Claire Cullen, Nolwenn Gontard, Nathalie Guilbert, Alev Gurbuz Cuneo, Rocky Kabeya, Justin Lushombo, Pamela Mallinga, Nadine Rudahindwa and Moussa Sawadogo. The authors also thank Natacha Lemasle and Verena Phipps-Ebeler for their support throughout the project.

Contributors JV was the principal investigator of the study. EK, RP and KLF contributed to the design, analysis and interpretation of findings. DR contributed to the implementation of the programme and oversight in DRC. MH provided study design support. All authors have reviewed and contributed to the final manuscript.

Funding This research was made possible through the generous financial support of the State and Peacebuilding Fund and the Nordic Trust Fund at the World Bank, as well as the World Bank's Umbrella Facility for Gender Equality.

Competing interests None declared.

Patient and public involvement Patients and/or the public were involved in the design, or conduct, or reporting, or dissemination plans of this research. Refer to the Methods section for further details.

Patient consent for publication Not required.

Ethics approval Ethical approval was received from IRC's Internal Review Board and the DRC Ministry of Women, Family, and Children.

Provenance and peer review Not commissioned; externally peer reviewed.

Data availability statement Data are available upon reasonable request to the study team.

Open access This is an open access article distributed in accordance with the Creative Commons Attribution Non Commercial (CC BY-NC 4.0) license, which permits others to distribute, remix, adapt, build upon this work non-commercially, and license their derivative works on different terms, provided the original work is properly cited, appropriate credit is given, any changes made indicated, and the use is non-commercial. See: http://creativecommons.org/licenses/by-nc/4.0/.

\section{ORCID iDs}

Mazeda Hossain http://orcid.org/0000-0002-1878-8145

Kathryn L Falb http://orcid.org/0000-0001-8254-3364

\section{REFERENCES}

1 World Health Organization. WHO multi-country study on women's health and domestic violence against women: summary report of initial results on prevalence, health outcomes, and women's responses. Geneva: WHO, 2005.

2 Murphy M, Blackwell A, Ellsberg M, et al. No safe place: a lifetime of violence for conflict-affected women and girls in South Sudan. London, UK: George Washington University \& International Rescue Committee, 2017.

3 Tlapek SM. Women's status and intimate partner violence in the Democratic Republic of Congo. J Interpers Violence 2015;30:2526-40.

4 Annan J, Brier M. The risk of return: intimate partner violence in Northern Uganda's armed conflict. Soc Sci Med 2010;70:152-9.

5 Stark L, Asghar K, Yu G, et al. Prevalence and associated risk factors of violence against conflict-affected female adolescents: a multi-country, cross-sectional study. J Glob Health 2017;7:010416.

6 Ellsberg M, Arango DJ, Morton M, et al. Prevention of violence against women and girls: what does the evidence say? Lancet 2015;385:1555-66.

7 Jewkes R, Flood M, Lang J. From work with men and boys to changes of social norms and reduction of inequities in gender relations: a conceptual shift in prevention of violence against women and girls. Lancet 2015;385:1580-9.

8 Doyle K, Levtov RG, Barker G, et al. Gender-transformative Bandebereho couples' intervention to promote male engagement in reproductive and maternal health and violence prevention in Rwanda: findings from a randomized controlled trial. PLoS One 2018;13:e0192756.

9 Abramsky T, Devries KM, Michau L, et al. The impact of SASA!, a community mobilisation intervention, on women's experiences of intimate partner violence: secondary findings from a cluster randomised trial in Kampala, Uganda. J Epidemiol Community Health 2016;70:818-25.

10 Hossain M, Zimmerman C, Kiss L, et al. Working with men to prevent intimate partner violence in a conflict-affected setting: a pilot cluster randomized controlled trial in rural Côte d'Ivoire. BMC Public Health 2014;14.

11 Buller AM, Peterman A, Ranganathan M, et al. A Mixed-Method review of cash transfers and intimate partner violence in low- and middle-income countries. World Bank Res Obs 2018;33:218-58.

12 Peterman A, Palermo T, Bredenkamp C. Estimates and determinants of sexual violence against women in the Democratic Republic of Congo. Am J Public Health 2011;101:1060-7.

13 Stark L, Ager A. A systematic review of prevalence studies of gender-based violence in complex emergencies. Trauma Violence Abuse 2011;12:127-34.

14 Slegh H, Barker G, Levtov R. Gender relations, sexual and genderbased violence and the effects of conflict on women and men in North Kivu, Eastern DRC: results from the international men and gender equality survey (IMAGES). Washington DC and Cape Town, South Africa: Promundo-US and Sonke Gender Justice, 2014.

15 Tappis H, Freeman J, Glass N, et al. Effectiveness of interventions, programs and strategies for gender-based violence prevention in refugee populations: an integrative review. PLOS Curr 2016;8. doi:10.1371/currents.dis.3a465b66f9327676d61eb8120eaa5499. [Epub ahead of print: 19 Apr 2016].

16 World Health Organization. Putting women first: ethical and safety recommendations for research on domestic violence against women. Geneva: WHO, 2001

17 Pierotti RS, Lake M, Lewis C. Equality on his terms: doing and undoing gender through men's discussion groups. Gend Soc 2018;32:540-62.

18 Glass N, Perrin NA, Kohli A, et al. Randomised controlled trial of a livestock productive asset transfer programme to improve economic and health outcomes and reduce intimate partner violence in a postconflict setting. BMJ Glob Health 2017;2:e000165.

19 Kohli A, Perrin N, Mpanano RM, et al. Family and community driven response to intimate partner violence in post-conflict settings. Soc Sci Med 2015;146:276-84. 
20 Falb KL, Annan J, King E, et al. Gender norms, poverty and armed conflict in Côte d'Ivoire: engaging men in women's social and economic empowerment programming. Health Educ Res 2014;29:1015-27.

21 Babcock JC, Costa DM, Green CE, et al. What situations induce intimate partner violence? A reliability and validity study of the proximal antecedents to violent episodes (PAVE) scale. J Fam Psychol 2004:18:433-42.

22 Stern E, Heise L, McLean L. Working with couples to prevent IPV: Indashyikirwa in Rwanda. London, UK, 2018. 